
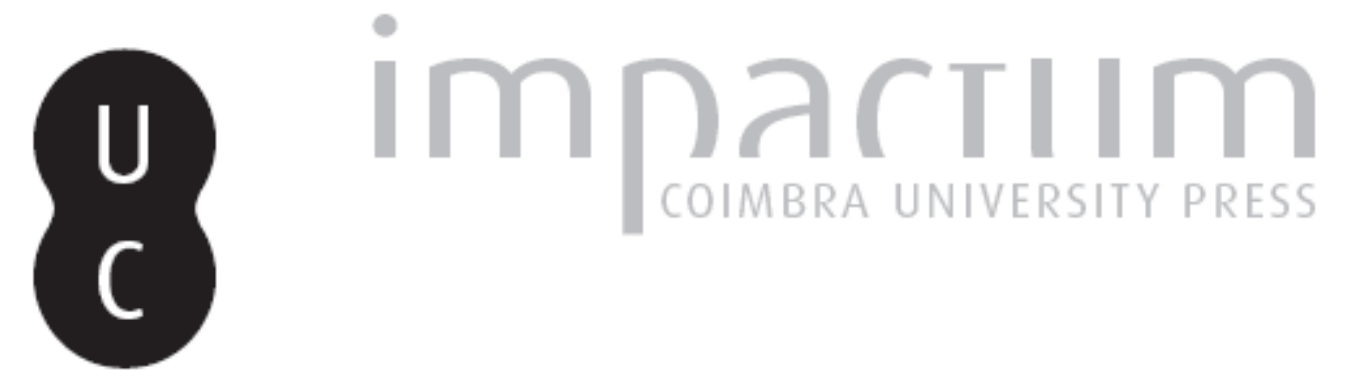

As figuras greco-romanas de Almada Negreiros na Cidade Universitária de Lisboa

Autor(es): $\quad$ Pascoal, Ana Mehnert

Publicado por: $\begin{aligned} & \text { Associação Portuguesa de Estudos Clássicos; Instituto de Estudos } \\ & \text { Clássicos }\end{aligned}$

URL

persistente:

URI:http://hdl.handle.net/10316.2/30359

DOI:

DOI:http://dx.doi.org/10.14195/0872-2110_55_12

Accessed : $\quad$ 26-Apr-2023 12:27:16

A navegação consulta e descarregamento dos títulos inseridos nas Bibliotecas Digitais UC Digitalis, UC Pombalina e UC Impactum, pressupõem a aceitação plena e sem reservas dos Termos e Condições de Uso destas Bibliotecas Digitais, disponíveis em https://digitalis.uc.pt/pt-pt/termos.

Conforme exposto nos referidos Termos e Condições de Uso, o descarregamento de títulos de acesso restrito requer uma licença válida de autorização devendo o utilizador aceder ao(s) documento(s) a partir de um endereço de IP da instituição detentora da supramencionada licença.

Ao utilizador é apenas permitido o descarregamento para uso pessoal, pelo que o emprego do(s) título(s) descarregado(s) para outro fim, designadamente comercial, carece de autorização do respetivo autor ou editor da obra.

Na medida em que todas as obras da UC Digitalis se encontram protegidas pelo Código do Direito de Autor e Direitos Conexos e demais legislação aplicável, toda a cópia, parcial ou total, deste documento, nos casos em que é legalmente admitida, deverá conter ou fazer-se acompanhar por este aviso.

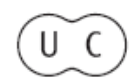




\section{Boletim de \\ Estudos Clássicos}

Associação Portuguesa de Estudos Clássicos

Instituto de Estudos Clássicos

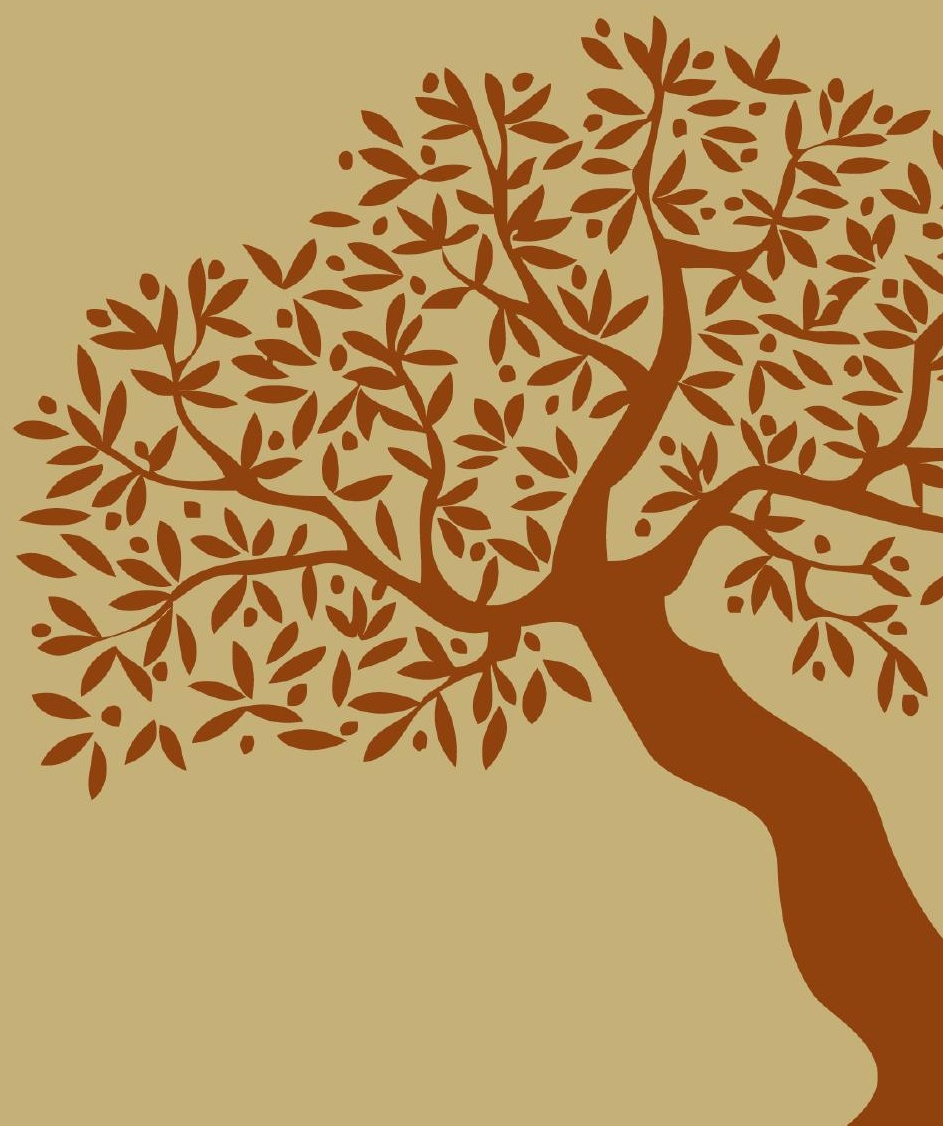

Coimbra

Junho de 2011 


\title{
As Figuras Greco-Romanas de Almada Negreiros NA CidAde UniversitáRIA de LISBOA
}

\author{
Há muita gente que conhece História, \\ mas nem todos conservam o instinto de \\ saber viajar pelo passado.
}

Almada Negreiros, $1935^{1}$

É célebre a longa colaboração entre o multifacetado artista José de Almada Negreiros (1893-1970) e um dos arquitectos que mais obra deixou em Lisboa no período do Estado Novo, Porfírio Pardal Monteiro (18971957). Dois espíritos obstinados, cuja amizade e afinidade laboral ficaram marcadas no espaço público, através de obras tão distintas como a Igreja de Nossa Senhora do Rosário de Fátima (1938), a sede do Diário de Notícias (1940), as gares marítimas de Alcântara (1942) e da Rocha do Conde de Óbidos (1945) ou o Hotel Ritz (1959) $)^{2}$. Estas diversificadas colaborações possibilitaram a Almada, enquanto decorador, o desenvolvimento de obras plásticas segundo técnicas tidas como ancestrais, como a pintura mural, o vitral e a tapeçaria mural, privilegiadas pelo regime para ornamentação dos seus edifícios públicos. No entanto, saliente-se que Almada não se enfileirou nos desígnios estéticos oficiais, avesso à «Política do Espírito» de António Ferro e aos certames do SPN/SNI, assumindo linhas de experimentação plástica muito pessoais. Pela mão de Pardal Monteiro, refere José-Augusto França que «Almada pôde entrar no circuito das encomendas de Estado» ${ }^{3}$, num período em que o mercado privado era restrito e praticamente inexistente em Portugal e as encomendas estatais constituíam um garante de subsistência.

1 J. Almada Negreiros, «Portugal oferece-nos o sentido de» (Sudoeste, $\mathrm{n}^{\circ} 1$, Junho 1935), Obras Completas V - Ensaios, Lisboa, 1992, 78.

2 Para uma breve reflexão sobre esta relação, vide R. Henriques da Silva, «Almada e Pardal Monteiro», J. Monterroso Teixeira (coord. cient.), Almada. A cena do corpo: catálogo de exposição, Lisboa, 1993, 195-199.

3 J.-A. França, Almada. O Português sem Mestre, Lisboa, 1974, 129. 
O artista recordou-o anos mais tarde, em homenagem pública ao arquitecto, considerando esta ligação, assente numa profunda admiração e amizade, «a maior e melhor colaboração da minha vida de artista» 4 .

O desejo de implementação de uma Cidade Universitária em Lisboa, criada de raiz, remonta, praticamente, à fundação da Universidade na capital em $1911^{5}$, tendo-se intensificado o debate acerca da sua necessidade no final dos anos 20. O projecto, acometido a Pardal Monteiro em meados da década de 30 e comportando três dos edifícios considerados possuidores das piores condições lectivas, a par do urgente Hospital Escolar - as Faculdades de Direito e de Letras e os serviços centrais da Reitoria -, apenas veio a ser inaugurado entre 1957 e $1961^{6}$. Este «núcleo fundador», respondendo ainda de certo modo aos desígnios arquitectónicos monumentalizantes do regime para os seus edifícios oficiais, empregando elementos como compactos pórticos de entrada com colunatas, recebeu um programa decorativo integrado com denominadores comuns: o elogio do Saber e o enobrecimento e legitimação da instituição universitária lisboeta e das suas raízes históricas. Em cada um dos edifícios, estas ideias transversais foram desdobradas, de acordo com as especificidades e o destino particular de cada um. Uma plêiade de artistas laborou neste empreendimento, tanto habituais participantes em obras patrocinadas pelo regime, como Leopoldo de Almeida, António Duarte, Martins Correia e Lino António, como artistas de novas gerações opostas às artes plásticas oficialmente valorizadas, como Rogério Ribeiro e Querubim Lapa. Variados recursos técnicos e iconográficos foram aplicados, atendendo a um programa decorativo cujas temáticas se estabeleceram superiormente, à imagem do que sucedeu na Cidade Universitária de Coimbra ${ }^{7}$, desejando-se

4 J. Almada Negreiros, «Duas palavras de um colaborador. Na homenagem ao arquitecto professor Pardal Monteiro», Obras Completas VI - Textos de Intervenção, Lisboa, 1993, 117.

5 A Universidade de Lisboa foi criada a par da Universidade do Porto através do Decreto com força de lei de 22 de Março de 1911, Diário do Governo, nº 68, 24 de Março de 1911, 1261-1262.

6 Sobre a evolução dos projectos arquitectónicos da Cidade Universitária de Lisboa e as diferentes etapas que pautaram a sua construção, vide, por exemplo, P. Santos Pedrosa, Cidade Universitária de Lisboa (1911-1950): génese de uma difícil territorialização, Lisboa, 2008.

7 Sobre esta questão, vide N. Rosmaninho, O Poder da Arte. O Estado Novo e a Cidade Universitária de Coimbra, Coimbra, 2006. 
obter um conjunto esteticamente harmónico. As peças artísticas integradas estiveram, desde a criação das maquetas de estudo, sob supervisão directa da Junta Nacional da Educação (JNE), através dos vogais da $1^{\mathrm{a}}$ subsecção da $6^{\mathrm{a}}$ secção, dedicada às Belas Artes ${ }^{8}$, entre os quais preponderaram o arquitecto Raul Lino e o escultor e crítico de arte Diogo de Macedo.

José de Almada Negreiros constituiu um caso particular neste conjunto, tendo sido o único artista a intervir nos três edifícios projectados por Pardal Monteiro. Para cada um dos pórticos pelos quais se faz a entrada nos edifícios ${ }^{9}$, Almada, contando então com mais de 60 anos de idade, concebeu desenhos coloridos que foram gravados nas placas pétreas que cobrem os seus alçados internos. O artista criara também um padrão para azulejo destinado a revestir os três edifícios, projecto que acabou por não ser aprovado, alegando-se a inadequação do azulejo, «material pobre», para estas construções que se desejavam imponentes e sóbrias ${ }^{10}$.

Pretende-se, neste artigo, uma análise das figuras greco-romanas que o artista concebeu para a Cidade Universitária de Lisboa. Almada, enquanto artista e teórico, valorizou a cultura clássica, em particular a herança da Grécia como berço da Europa, centrando o seu pensamento numa retoma de valores e tomando como referências figuras como Pitágoras e Aristóteles, interpretando-as, e integrando paralelamente termos como tekhné, kanon ou

8 A Junta Nacional da Educação foi criada em 1936, aquando da remodelação do Ministério da Instrução Pública para Ministério da Educação Nacional, com vista ao «estudo de todos os problemas que interessam à formação do carácter, ao ensino e à cultura» (Lei $\mathrm{n}^{\mathbf{o}}$ 1941, 11-IV-1936). A $6^{\mathrm{a}}$ secção respeitava às Belas Artes, destacando-se neste caso a $1^{a}$ subsecção, dedicada a supervisionar Artes Plásticas, Museus e Monumentos (Decreto-lei no 26611, 19-V-1936).

9 Nas Faculdades de Direito e de Letras existe apenas um pórtico, respectivamente, sendo que no caso da Reitoria, por existirem duas entradas opostas, existem dois pórticos, ambos decorados por Almada Negreiros.

10 Os azulejos chegaram a ser apostos numa moradia no Restelo, em Lisboa. Sobre o almejado revestimento azulejar da Cidade Universitária de Lisboa, vide A. Mehnert Pascoal, A Cidade do Saber. Estudo do Património Artístico Integrado nos edificios projectados pelo arquitecto Porfírio Pardal Monteiro para a Cidade Universitária de Lisboa (1934-1961), Lisboa, 2010, 160-163. 
théleon numa teoria artística muito particular ${ }^{11}$. Como o expôs José-Augusto França, «foi sempre por outras vias que o pensador atingiu o seu pensamento, muito menos por leitura aturada que por meditação "ingénua" ${ }^{12}$. No caso da Cidade Universitária lisboeta, uma obra patrocinada pelo Governo terminada já nos inícios da década de 60, intenta observar-se a forma como o artista materializou personagens históricas e mitológicas, que tanto o fascinaram nas suas indagações pessoais, inseridas num programa decorativo superiormente delineado e controlado.

\section{Faculdade de Direito: As origens históricas e filosóficas do Direito}

A Faculdade de Direito, inaugurada em 1957, tem especial interesse no que concerne a representações greco-romanas. As gravuras, cuja incisão se fez em 1958, narram uma viagem histórica através da disciplina, evidenciando momentos e personagens decisivas para a sua definição. Almada decorou cada fachada com um conjunto de figuras que se reportam a quatro marcos distintos desta temática: as origens do Direito, a sua concepção transcendente, a construção romana do Direito e a transição, e, finalmente, fixou «o Direito Português e a sua História através de grandes figuras representativas» ${ }^{13}$, onde não se incluem figuras greco-romanas.

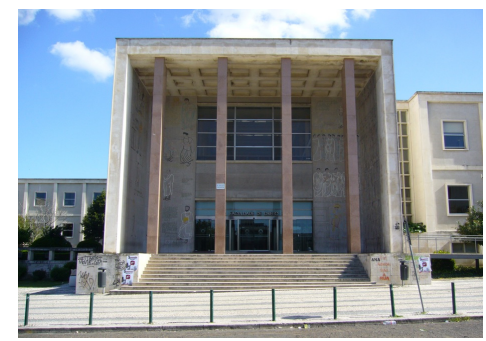

Fig, 1 - Pórtico de entrada da Faculdade de Direito da Universidade de Lisboa. Fotografia: A. M. Pascoal, 2010.

11 Sobre este assunto, vide L. F. N. A. Castro, Almada Negreiros: Herança Grega e Teoria das Proporções Harmónicas, 2 vols., Tese de Mestrado em Teorias da Arte, Faculdade de Belas Artes da Universidade de Lisboa, 2003.

12 J.-A. França, op. cit., 10.

13 Cf. MOP/CANIU, O Novo Edifício da Faculdade de Direito, Lisboa, s/n, 1957, s/paginação. 
As gravuras aplicadas nesta Faculdade assumem particularidades face aos restantes edifícios, destacando-se através do acompanhamento de legendas elucidativas, por vezes citando excertos literários. Nos estudos prévios, os passos apresentavam-se bem mais extensos, ocupando por vezes maior superfície do que as próprias personagens, facto que mereceu alguma reticência por parte do vogal da JNE que os controlou, o professor e pintor Armando de Lucena. Emitiu um parecer favorável relativamente aos desenhos, abstendo-se, porém, quanto às legendas, «de dar parecer sobre o seu conteúdo jurídico ou filosófico que não é sua atribuição mas de outros órgãos competentes, votando, todavia, que sob o ponto de vista decorativo, algumas (...) se afigurem demasiado extensas e compactas para constituírem um complemento decorativo que lhes poderia caber» ${ }^{14}$. De facto, comparativamente aos desenhos iniciais, a obra final apresenta-se mais contida, tendo o artista optado em várias cenas por substituir a densa inscrição de texto por uma mera alusão à obra literária. Quanto às legendas, foram introduzidas nos estudos em língua portuguesa, condensadas e substituídas na obra final pelas versões nos idiomas originais - acádico, hebraico, grego e latim. Se este reparo por parte dos órgãos fiscalizadores levou a que Almada Negreiros modificasse em parte o que idealizara, mencione-se que lhe foi vedada a possibilidade de enquadrar no espaço sobranceiro à porta de entrada do edifício referências às suas teorias numérico-filosóficas, concretamente a «relação 9/10» e «pintar o sete» ${ }^{15}$, censuradas pelos responsáveis ${ }^{16}$ - facto de que o artista se queixou publicamente ${ }^{17}$. O espaço permanece, até hoje, sem decoração.

14 ANTT, Junta Nacional da Educação, Actas das Sessões da $1^{\text {a }}$ Subsecção da

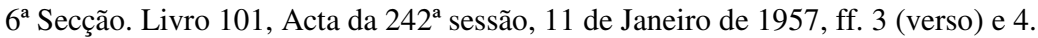

15 Almada veio a concretizar estes temas, fruto de ponderada reflexão, no painel «Começar» (1968-69), colocado no átrio da Fundação Calouste Gulbenkian, bem como em pinturas a óleo, de carácter abstracto, expostas no I Salão da Fundação Calouste Gulbenkian em 1957. Sobre estas especulações teóricas do artista, vide, por exemplo, J. Almada Negreiros, Ver, Lisboa, Arcádia, 1982, e L. F. N. A. Castro, op. cit.

16 Cf. J. Vieira, Almada Negreiros, colecção «Fotobiografias Século XX», Lisboa, 2001, 174.

17 Cf. «Prémio "Diário de Notícias". Almada Negreiros recebeu ontem o galardão», Diário de Notícias, n 35941, 22-III-1966, 1. 
No conjunto inciso, no âmbito das origens da disciplina, são destacadas duas figuras gregas, representadas de forma estilizada e diferenciadas das demais especialmente através do vestuário: Pitágoras de Samos, que muito interessava a Almada, e Heraclito de Éfeso.

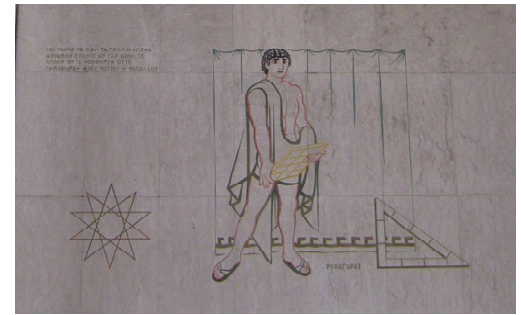

Fig. 2 - Pitágoras, gravura incisa, 1958.

Fotografia: A. M. Pascoal, 2010.

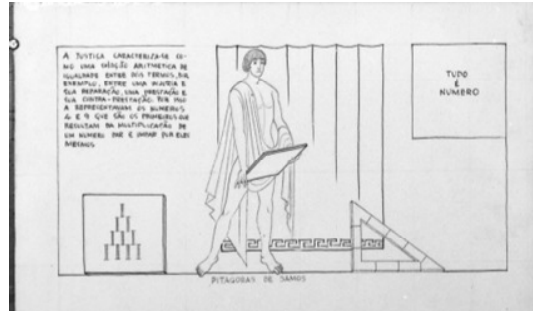

Fig. 3 - Pitágoras, desenho, sem data. Fotografia: Mário Novais, sem data. Biblioteca de Arte da Fundação Calouste Gulbenkian, Colecção Estúdio Mário Novais, cota: CFT003.5395-5399.

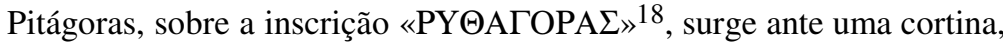
num cenário semelhante ao do estudo prévio; acompanhado por um triângulo rectângulo em alusão à formulação do teorema, segura uma tábua nas mãos. Na passagem à pedra desapareceu a inclusão de uma representação peculiar do tetraktys ${ }^{19}$, estando no seu lugar dois pentagramas sobrepostos. Pitágoras está representado enquanto impulsionador da definição de «justiça aritmética», que quantifica o objectivo final do Direito, cuja definição surgia no desenho de estudo: «A justiça caracteriza-se como uma relação aritmética de igualdade entre dois termos, por exemplo, entre uma injúria e sua reparação, uma prestação e sua contra-prestação. Por isso a representavam os números 4 e 9 que são os primeiros que resultam da multiplicação de um número par e ímpar por eles mesmos». Na composição final, perdeu-se também a legenda «Tudo é número», tendo ambas as frases sido substituídas por um fragmento do pitagórico Filolau de Crotona, inscrito em grego: «E o

18 Almada, ao inscrever o nome de Pitágoras em grego, cometeu um erro de simpatia, erudito, estando inscrito «Ritágoras», devido à confusão entre o «P» e o «R» grego. Deste facto alertou-nos o Prof. Doutor N. Simões Rodrigues.

19 Esta figura veio a ser incluída numa tapeçaria mural chamada «O Número», junto ao nome de Pitágoras, peça executada também em 1958, pela Manufactura de Tapeçarias de Portalegre, para o Tribunal de Contas, Lisboa. 
certo é que todas as coisas que se conhece têm número; pois sem ele nada se pode pensar ou conhecer» 20 .

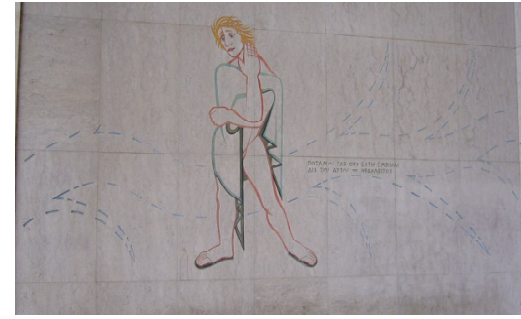

Fig. 4 - Heraclito, gravura incisa, 1958.

Fotografia: A. M. Pascoal, 2010.

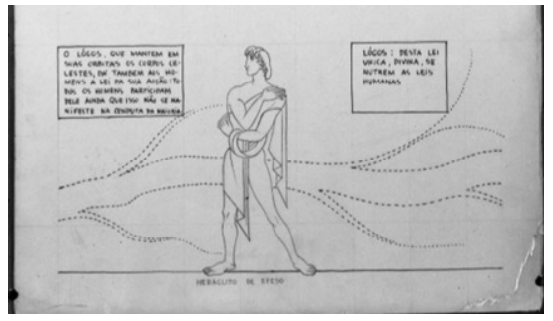

Fig. 5 - Heraclito, desenho, sem data.

Fotografia: Mário Novais, sem data. Biblioteca de Arte da Fundação Calouste Gulbenkian, Colecção Estúdio Mário Novais, cota: CFT003.5395-5399.

Por seu turno, Heraclito de Éfeso está posicionado frente a um rio, meramente aludido, pois foi fixado a tracejado; acompanha-o um fragmento que lhe é atribuído, relativo ao devir natural: «Não é possível entrar duas vezes no mesmo rio» ${ }^{21}$. Curiosamente, o pintor pensara adicionar duas legendas, aparentemente atribuídas a Heraclito, referentes ao lógos, considerado como lei suprema que rege a conduta humana 22 .

É interessante notar que se optou pela representação de personagens gregas não directamente ligadas à implementação do Direito; ao invés de retratar, por exemplo, Drácon e Sólon, Almada introduziu figuras que, embora relacionáveis com questões de justiça, o interessavam particularmente no que toca a teorizações em torno do número e da geometria.

20 Fragmento reproduzido em Estobeu, Anth. I, 21, 7 b. Tradução de C. A. Louro Fonseca em G. Kirk et al., Os Filósofos Pré-Socráticos. História crítica com selecção de textos, Lisboa, ${ }^{4} 1994$, 344. Almada Negreiros também introduziu esta citação nos seus textos compilados na já citada colectânea póstuma Ver, p. 213.

21 Tradução de A. Costa, Heraclito, Fragmentos contextualizados, Lisboa, $2005,147$.

22 À esquerda da figura, «O lógos, que mantém em suas órbitas os corpos celestes, dá também aos homens as leis da sua acção: todos os homens participam dele ainda que isso não se manifeste na conduta da maioria», e, à direita, «Lógos: desta lei única, divina, se nutrem as leis humanas». 


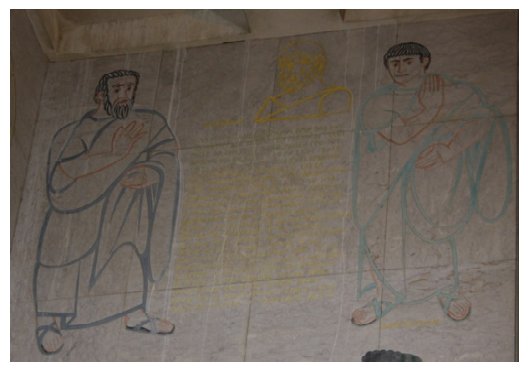

Fig. 6 - Sócrates, Platão e Aristóteles, gravura incisa, 1958 .

Fotografia: A. M. Pascoal, 2010.

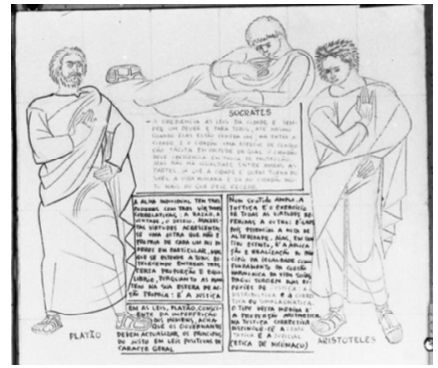

Fig. 7 - Sócrates, Platão e Aristóteles, desenho, sem data.

Fotografia: Mário Novais, sem data. Biblioteca de Arte da Fundação Calouste Gulbenkian, Colecção Estúdio Mário Novais, cota: CFT003.5395-5399.

$\mathrm{Na}$ fachada seguinte estão representadas personagens históricas relacionadas com a «concepção transcendente do Direito», figurando teorizações patentes em obras gregas e romanas. No topo encontra-se um conjunto de três figuras, bastante distintas quanto ao estudo prévio no que toca ao desenho, mas sobretudo díspares quanto à inclusão textual. No pórtico observamos Platão, barbado, e Aristóteles, ambos de pé e envergando togas, e um busto retratando Sócrates no cimo da composição, rodeando um passo em grego de Críton, de Platão ${ }^{23}$. Na versão de estudo, Sócrates aparece como uma figura deitada no topo da cena, de atitude reflexiva. A cada uma das três personagens, Almada desejara conferir longas citações - para

23 Críton, 54b-d: «Sócrates, deixa-te persuadir por nós, que te criámos, e não faças mais caso da vida e dos filhos, nem do que quer que seja, além da justiça, a fim de que, indo para o Hades, tenhas todos estes argumentos em tua defesa perante os que lá governam. Pois, ao fazeres o que te propõem, nem aqui te parecerá melhor, nem mais justo, nem mais piedoso, nem para nenhum dos teus, nem, lá chegando, será melhor. Pelo contrário, se deixares esta vida agora, ir-te-ás embora, tendo sido injustiçado, não por nós, as leis, mas pelos homens. E, se fugires, retribuindo assim o mal com o mal, e fazendo-o por tua vez, violando acordos e tratados que fizeste connosco, fazendo mal a esses, a quem menos devias fazer, a ti próprio e aos amigos, à pátria e a nós, nós te tornaremos a vida dura, e além, as nossas irmãs, no Hades, não te receberão bem, vendo que, por ti, intentaste destruir-nos. Mas não te deixes persuadir, fazendo o que Críton diz, mais que o que nós dizemos». Tradução de J. Trindade Santos, Platão, Êutifron, Apologia de Sócrates, Críton, Lisboa, ${ }^{3} 1992,127$. 
Sócrates, inseriu também um passo de Críton $^{24}$, para Platão colocou duas frases $^{25}$ e para Aristóteles menciona Ética a Nicómaco ${ }^{26}$ - certamente, foi impedido pelos órgãos supervisores das obras de colocar tamanhas inscrições textuais.

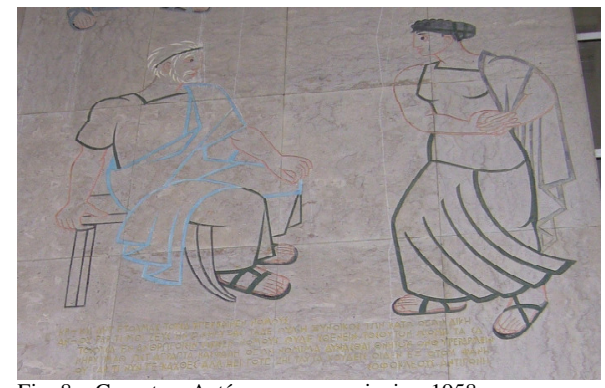

Fig. 8 - Creonte e Antígona, gravura incisa, 1958.

Fotografia: A. M. Pascoal, 2010.

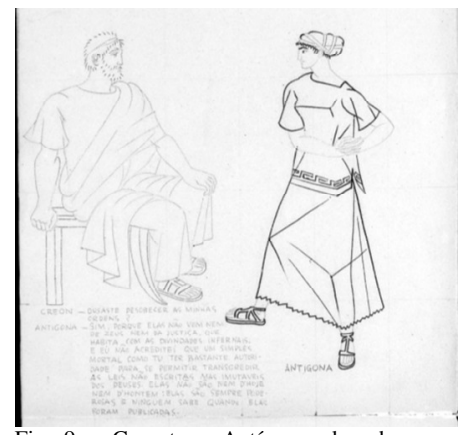

Fig. 9 - Creonte e Antígona, desenho, sem data.

Fotografia: Mário Novais, sem data. Biblioteca de Arte da Fundação Calouste Gulbenkian, Colecção Estúdio Mário Novais, cota: CFT003.5395-5399.

24 «A obediência às leis da cidade é sempre um dever e para todos, até mesmo quando elas estão contra um, há entre a cidade e o cidadão uma espécie de condição tácita em virtude da qual o cidadão deve obediência em troca de protecção. Mas não há igualdade entre ambas as partes, já que é a cidade quem torna possível a vida humana e dá ao cidadão muito mais do que dele recebe».

25 «A alma individual tem três poderes com três virtudes correlativas: a razão, a vontade, o desejo. Mas a estas virtudes acrescenta-se uma outra que não é própria de cada um dos poderes em particular, mas que se estende a todos estabelecendo entre os três certa proporção e equilíbrio, porquanto as mantém na sua esfera de acção própria: é a justiça», e «Em As Leis, Platão, consciente da imperfeição dos homens, acha que os governantes devem actualizar os princípios do justo em leis positivas de carácter geral».

26 «Num sentido amplo, a justiça é o exercício de todas as virtudes referidas a outro: é-lhes pois essencial a nota de alteridade. Mas, em sentido estrito, é a aplicação e a realização do princípio da igualdade como fundamento da coesão harmónica da vida social. Daqui surgem duas espécies de justiça: a distributiva e a correctiva ou sinalagmática. O tipo desta medida é a proporção aritmética. Na justiça correctiva distingue-se a comutativa e a judicial (Ética de Nicómaco)». 
No seguimento da fachada, estão Creonte e Antígona, constituindo uma menção à tragédia Antígona, de Sófocles; as duas figuras enquadram um excerto do diálogo, inscrito em grego, no qual Antígona defende a prevalência das leis imutáveis dos deuses sobre a lei escrita do Homem ${ }^{27}$, estando Creonte sentado, de barbas brancas, e Antígona de pé, do lado direito. Neste caso, trata-se do passo que, desde início, Almada pretendeu inserir $^{28}$, diferindo apenas quanto à língua em que foi fixado.

Por baixo desta cena, alude-se a Cícero, representado com o braço direito erguido, cabelo rapado e envergando uma toga branca e sandálias romanas, bem como aos seus escritos: junto aos seus pés, um quadrado com a inscrição De Officiis (Dos Deveres), o único que permaneceu dos três que o artista planeou. Assim, em vez de menções ao Tratado da República (De Republica) e As Leis (De Legibus), foram inscritas citações de cada uma destas obras ${ }^{29}$, divergentes das colocadas no desenho de estudo ${ }^{30}$.

27 Estão inscritos os vv. 449-457: «CREONTE - E ousaste, então, tripudiar sobre estas leis?/ANTÍGONA - É que essas não foi Zeus que as promulgou, nem a Justiça, que coabita com os deuses infernais, estabeleceu tais leis para os homens. E eu entendi que os teus éditos não tinham tal poder, que um mortal pudesse sobrelevar os preceitos, não escritos, mas imutáveis dos deuses. Porque esses não são de agora, nem de ontem, mas vigoram sempre, e ninguém sabe quando surgiram». Tradução do original grego de M. H. da Rocha Pereira, Sófocles, Antígona, Lisboa, ${ }^{6} 1992$, 56-57.

28 «CREON - Ousaste desobedecer as minhas leis? / ANTÍGONA - Sim, porque elas não vêm nem de Zeus nem da Justiça, que habita com as divindades infernais. E eu não acreditei que um simples mortal como tu ter bastante autoridade para se permitir transgredir as leis não escritas mas imutáveis dos deuses. Elas não são nem d'hoje nem d'hontem: elas são sempre poderosas e ninguém sabe quando elas foram publicadas».

29 De Legibus, 1.18: «A lei é a norma suprema que, inserida na Natureza, determina o que se deve fazer e proíbe o seu contrário", tradução de N. Simões Rodrigues. De Republica 3.22.33: «Há uma lei verdadeira, a recta razão, que está de acordo com a natureza, é repartida por todos, é constante, sempiterna», tradução do original latino de M. H. da Rocha Pereira, Romana. Antologia da Cultura Latina, Porto, 2005, 51.

30 Almada apontara, à esquerda de Cícero, «A ciência do Direito não nasce dos éditos dos pretores ou das leis das doze tábuas, mas do seio da filosofia // Ex intima filosofia», e, à sua direita, «A lei não é invenção do engenho humano, nem da vontade dos povos... É o espírito de Deus, a sua razão soberana». 


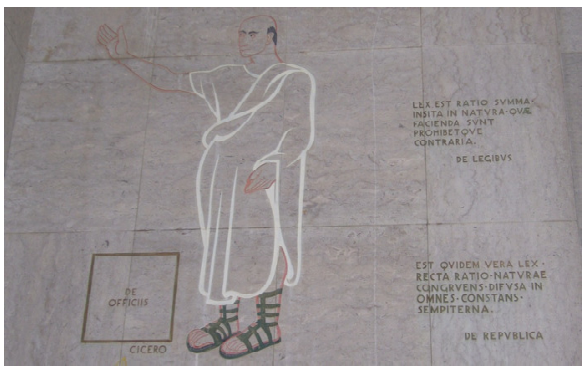

Fig. 10 - Cícero, gravura incisa, 1958.

Fotografia: A. M. Pascoal, 2010.

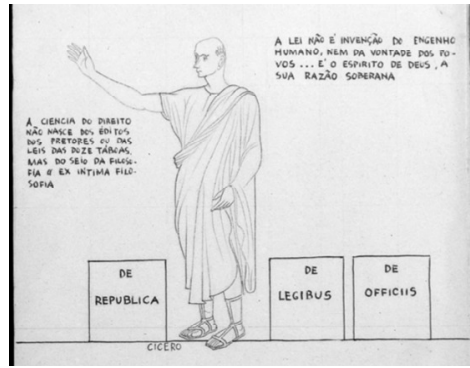

Fig. 11 - Cícero, desenho, sem data.

Fotografia: Mário Novais, sem data. Biblioteca de Arte da Fundação Calouste Gulbenkian, Colecção Estúdio Mário Novais, cota: CFT003.5395-5399.

A «construção romana do Direito», na fachada seguinte do pórtico, inicia-se com a representação do mito fundacional de Roma, figurando Rómulo e Remo amamentados por uma loba - imagem que terá, provavelmente, tomado como fonte a escultura em bronze da Loba do Capitólio.

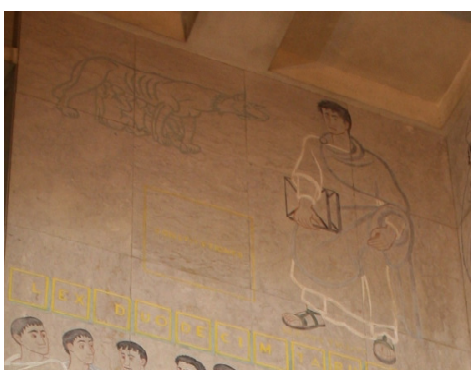

Fig. 11 - Rómulo e Remo amamentados pela Loba e Sérvio Túlio, gravura incisa, 1958. Fotografia: A. M. Pascoal, 2010.

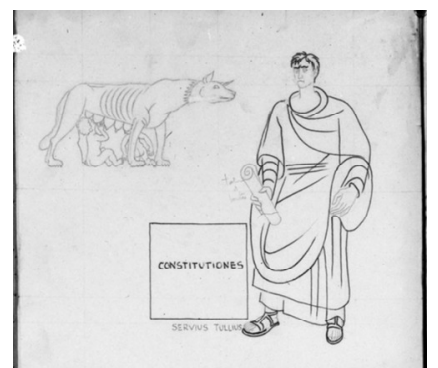

Fig. 12 - Rómulo e Remo amamentados pela Loba e Sérvio Túlio, desenho, sem data.

Fotografia: Mário Novais, sem data. Biblioteca de Arte da Fundação Calouste Gulbenkian, Colecção Estúdio Mário Novais, cota: CFT003.5395-5399.

Junto à loba, foi posicionado Sérvio Túlio, sob a legenda «Servius Tullius», ao qual se atribui uma reforma assinalável a nível da constituição, representada por Almada através de um quadrado amarelo com a inscrição «Constitutiones». O sexto rei de Roma, que encetou importantes alterações na sua organização política e administrativa, criando assim as bases da 
República ${ }^{31}$, surge com tábuas nas mãos, ao invés do pergaminho enrolado previsto no desenho inicial.

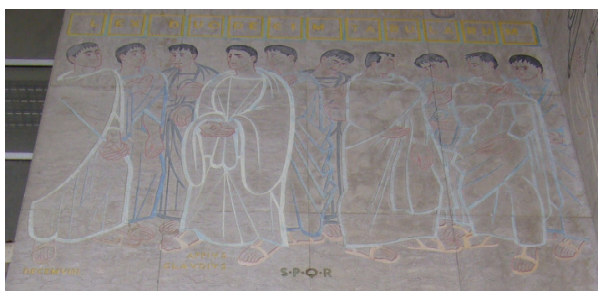

Fig. 13 - Decênviro e Lei das XII Tábuas, gravura incisa, 1958. Fotografia: A. M. Pascoal, 2010.

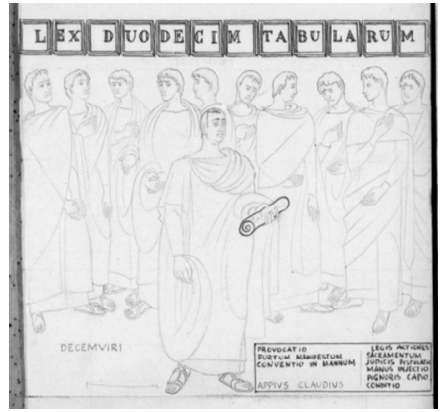

Fig. 14 - Decênviro e Lei das XII Tábuas, desenho, sem data.

Fotografia: Mário Novais, sem data. Biblioteca de Arte da Fundação Calouste Gulbenkian, Colecção Estúdio Mário Novais, cota: CFT003.5395-5399.

$\mathrm{Na}$ sequência imediata observam-se dez figuras masculinas, sob a inscrição «Lex Duodecim Tabularum» - menção à promulgação da Lei das Doze Tábuas, o primeiro compêndio escrito de leis romanas, fonte de todo o Direito público e privado segundo Tito Lívio ${ }^{32}$. Esses dez legisladores constituíram o primeiro Decênviro, conduzidos por Ápio Cláudio, destacado no grupo através de legenda. Curiosamente, no estudo prévio, este jurista

31 Atribui-se a Sérvio Túlio (séc. VI a.C.) a divisão da sociedade romana segundo cinco classes censitárias, conforme o rendimento, levando consequentemente a mudanças de vulto no que respeita ao direito de voto e à criação de comitia centuriata. Instituiu quatro tribos urbanas, nas quais se incluíram os plebeus. A reforma também se aplicou ao exército, composto por falanges de hoplitas. Sobre este assunto, vide, por exemplo, F. Martino, Storia della Constituzione Romana I, Nápoles, ${ }^{2} 1972,161-201$.

32 3.34: «(...) a lei das Dez Tábuas foi considerada perfeita e submetida aos comícios centuriatos que a aprovaram. No imenso acervo de leis acumuladas umas sobre as outras no decorrer dos tempos, elas continuam a ser, até hoje, a fonte de todo o direito público e privado.» 
distingue-se por estar colocado em frente dos restantes homens ${ }^{33}$, ostentando um pergaminho, enrolado, nas mãos; em adição, Almada colocara legendas alusivas às citadas disposiçõos legais ${ }^{34}$, que se perderam na versão final. Este grupo está sob a inscrição «SPQR», acrónimo de Senatus Populusque Romanus, designação oficial do Estado romano, em referência à República.

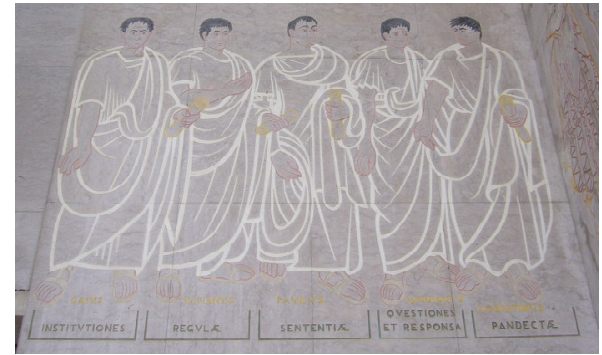

Fig.15 - Gaio, Ulpiano, Paulo, Papiniano e Modestino, gravura incisa, 1958.

Fotografia: A. M. Pascoal, 2010.

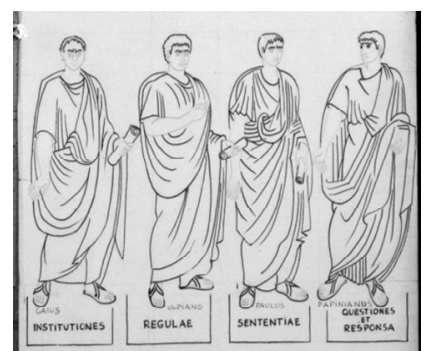

Fig. 16 - Gaio, Ulpiano, Paulo, Papiniano e Modestino, desenho, sem data.

Fotografia: Mário Novais, sem data. Biblioteca de Arte da Fundação Calouste Gulbenkian, Colecção Estúdio Mário Novais, cota: CFT003.5395-5399.

Finalmente, colocados sobre o espaço que coube ao Imperador bizantino Justiniano I, encontram-se cinco homens de toga segurando pergaminhos, ao invés dos quatro presentes no estudo ${ }^{35}$. São juristas dos séculos II e III que ocuparam cargos administrativos relevantes, cuja actividade foi decisiva no desenvolvimento da jurisprudência no Império e influenciou as gerações seguintes, e estão acompanhados de referências às respectivas obras: Gaio (Institutiones), Domício Ulpiano (Regulae), Paulo (Sententiae), Papiniano (Questiones et Responsa) e Modestino (Pandectae).

Esta viagem cadenciada pelo Direito através dos tempos, cronologicamente linear, é particularmente rica em figuras greco-romanas, tendo em atenção as bases constitutivas da disciplina. Saliente-se, apesar do

33 Em número de dez, e não nove como o grupo que ficou fixado, se exceptuarmos Ápio Cláudio.

34 Almada Negreiros colocou as seguintes referências junto a Ápio Cláudio: «Prouocatio, Furtum Manifestum, Conventio in Mannum / Legis Actiones: Sacramentum, Judicis Postulatio, Magnus Injectio, Pignoris Capio, Conditio».

35 No desenho prévio somente figuram Gaio, Ulpiano, Paulo e Papiniano. 
ligeiro estatismo das figuras e da compartimentação necessária das cenas, bem como do facto de maior pormenor se evidenciar nos estudos prévios, a perícia do artista e a sua capacidade exímia enquanto desenhador, que se denota no conjunto dos edifícios.

\section{Faculdade de Letras: Emblemas da literatura universal}

A incisão das gravuras no pórtico de entrada da Faculdade de Letras foi realizada no ano de 1961, três anos após a inauguração do edifício na Cidade Universitária. Almada Negreiros elaborou um profuso programa, análogo ao da Faculdade de Direito, conquanto apresenta uma evolução histórica: «figuras e alegorias do pensamento e da literatura universal e portuguesa» 36 , dos primórdios à contemporaneidade, povoam as fachadas. Porém, segundo José-Augusto França, esta obra terá tido «menos interesse para o artista, com as suas ilustrações literárias» ${ }^{37}$, porquanto esta temática não se propiciava à comunicação das suas teorizações acerca do número - de qualquer modo seria, certamente, mais uma vez impedido de concretizá-las, caso demonstrasse essa intenção.

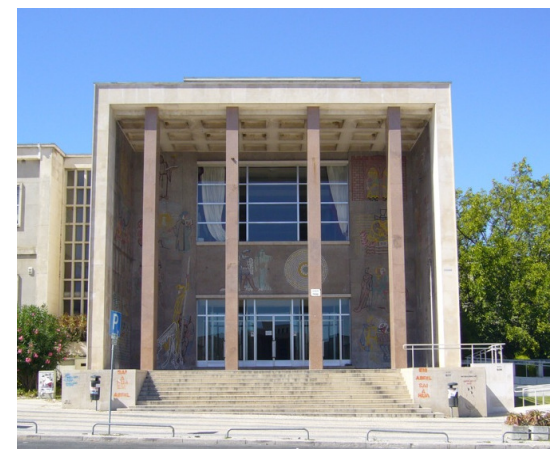

Fig, 17 - Pórtico de entrada da Faculdade de Letras da Universidade de Lisboa.

Fotografia: A. M. Pascoal, 2009.

36 «Almada - do Genesis a Fernando Pessoa», Suplemento Vida Literária 157, Diário de Lisboa, $\mathrm{n}^{\circ}$ 13872, 27-VII-1961, 15.

37 J.-A. França, op. cit., 170. 
Também para este edifício foi possível detectar um estudo prévio desenhado, que terá sido apresentado para aprovação à Junta Nacional da Educação ${ }^{38}$. No entanto, o número de figuras greco-romanas é bastante inferior ao de Direito, sendo que as grandes diferenças face ao resultado final não se detectam neste pequeno núcleo. Refira-se que na gravação na pedra se perderam as legendas existentes no estudo, que permitiriam ao observador uma identificação imediata das cenas retratadas.

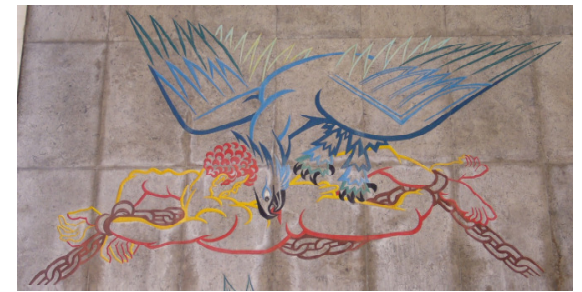

Fig. 18 - Prometeu agrilhoado, gravura incisa, 1961. Fotografia: A. M. Pascoal, 2009.

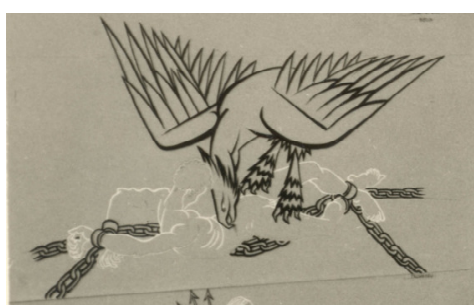

Fig. 19 - Prometeu agrilhoado, desenho, sem data.

Fotografia: Horácio Novais, sem data. Secretaria Geral do Ministério da Educação, Núcleo do Arquivo Técnico das Construções Escolares, Saco 2 «Faculdade de Letras».

Neste hino à Literatura desde os primórdios da Humanidade, as figuras correspondentes a obras legadas pela Antiguidade Clássica localizam-se na primeira fachada. Após a figuração das origens no Livro do Génesis, com a expulsão de Adão e Eva do Paraíso, Almada representou Prometeu agrilhoado, segundo a peça atribuída a Ésquilo ${ }^{39}$ : num pico rochoso do

38 Trata-se de uma fotografia da autoria de Horácio Novais, existente no espólio da Secretaria Geral do Ministério da Educação, Núcleo do Arquivo Técnico das Construções Escolares. No catálogo da exposição Almada. A cena do corpo, está reproduzida uma nota manuscrita com a divisão do pórtico por cenas, com indicação das obras literárias a fixar; para o caso das figuras greco-romanas, não se registam alterações quer quanto à fotografia, quer quanto ao resultado final: «Prometeu», «Homero (Ulisses e Neptuno)» e «Palinuro (Eneias e o Leme) Livro V, Eneida», são as referências escritas (p. 233).

39 Corresponde aos vv. 1020-1030: «Mas o cão alado de Zeus, a águia ensanguentada, voraz, o teu corpo rasgará e fará em farrapos - e devorará o teu fígado negro e já roído». Tradução de A. P. Quintela Sottomayor, Ésquilo, Prometeu Agrilhoado, Lisboa, 2008, 82. 
Cáucaso, com os pés e mãos acorrentados por grilhões, Prometeu, de caracóis rubros e rosto vergado sobre o peito, é atacado pela enorme águia, em tons de azul, ave enviada por Zeus que incessantemente lhe devora o fígado, constantemente renovado, como punição pela traição de ter provido fogo aos mortais. É curioso o facto de que, tanto no estudo como na gravura incisa, os pés de Prometeu, cruzados, tenham sido desenhados de forma errada, isto é, o direito como sendo o esquerdo e vice-versa.

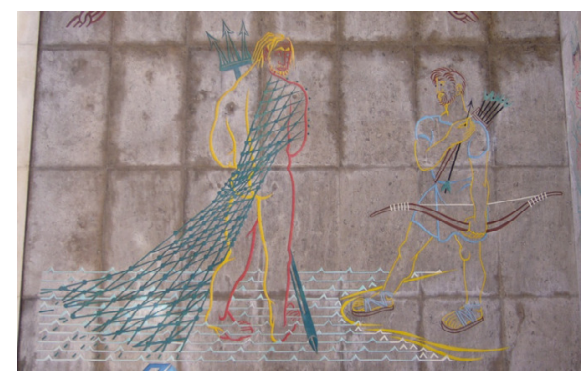

Fig. 20 - Posídon e Ulisses, gravura incisa, 1961.

Fotografia: A. M. Pascoal, 2009.

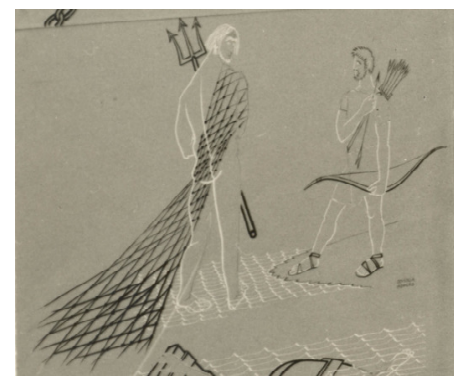

Fig. 21 - Posídon e Ulisses, desenho, sem data. Fotografia: Horácio Novais, sem data. Secretaria Geral do Ministério da Educação, Núcleo do Arquivo Técnico das Construções Escolares, Saco 2 «Faculdade de Letras».

A cena imediatamente por baixo refere-se à Odisseia, atribuída a Homero, representando Ulisses perante Posídon, numa ambiência marítima. Ao longo da narrativa, Posídon, irado, intenta a todo o custo evitar o regresso de Ulisses a Ítaca; Almada Negreiros gravou o momento em que se confrontaram $^{40}$. O deus, com os pés no mar e as costas voltadas para o observador, é identificado pelo tridente e por uma rede de pesca, que o cobre; em terra, Ulisses observa-o, segurando o seu arco ofertado por Ífito e carregando flechas. Segue-se uma cena de outra magna epopeia, a Eneida, de Vergílio. Está retratado um episódio que é relatado a Eneias durante a sua

40 O confronto entre ambos dá-se no Canto V, quando Posídon «reuniu as nuvens; e segurando na mão/o tridente, encrespou o mar. Incitou de todos os lados/toda a espécie de ventos e escondeu com nuvens/tanto a terra como o mar» (vv. 282-460). Tradução de Frederico Lourenço, Homero, Odisseia, Lisboa, ${ }^{6} 2005$, 99104. 
catábase, por Palinuro ${ }^{41}$, o único que pereceu durante a viagem em direcção a Itália, lançado aos mares pelo Sono: o timoneiro do navio de Eneias, desnudo, agarra-se a um leme ${ }^{42}$, único despojo do barco que se afundara nos mares, tendo desaparecido a outra peça que Almada colocou no desenho prévio.

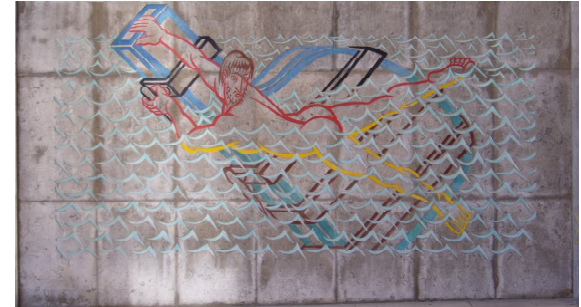

Fig. 22 - Palinuro, gravura incisa, 1961.

Fotografia: A. M. Pascoal, 2009.

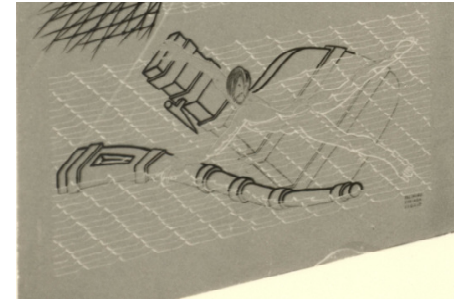

Fig. 23 - Palinuro, desenho, sem data. Fotografia: Horácio Novais, sem data. Secretaria Geral do Ministério da Educação, Núcleo do Arquivo Técnico das Construções Escolares, Saco 2 «Faculdade de Letras».

Constituindo apenas uma parcela da composição total, as figuras grecoromanas nesta Faculdade enquadram-se no espírito global de representação de momentos de confronto e tensão; no fundo, a ilustração da vitória do Bem sobre o Mal. As personagens escolhidas para este período específico, plenamente identificáveis com a sua fonte escrita, reportam-se a obras consideradas basilares da cultura universal e do pensamento ocidental, ainda actualmente objecto de estudo em diversos cursos ministrados nesta Faculdade. É de salientar que os casos de Prometeu e de Homero, também aqui fixados, eram particularmente caros a Almada Negreiros, entendidos

41 6.349-356: «Na verdade arrastei comigo, ao cair, o leme que me agarrava, debruçado sobre ele, vigiando e orientando a rota, quando este foi ocasionalmente sacudido com grande força. (...) Por três noites de borrasca o vento violento me arrastou nas águas, através do mar sem fim. Só ao quarto vislumbrei a Itália, do alto da crista de uma onda». Tradução de L. Cerqueira, Vergílio, Eneida, Lisboa, ${ }^{2} 2005$, 115.

42 5.859-860: «Mal o súbito torpor lhe começara a relaxar os membros quando o Sono, inclinado sobre ele, o lançou de cabeça às águas transparentes, levando consigo uma parte arrancada à popa e o leme e chamando em vão pelos companheiros». ibidem, 105. 
como marcos civilizacionais da Europa e cerne das suas especulações filosóficas e artísticas ${ }^{43}$.

\section{Reitoria: Consagração da «Casa do Saber»}

O edifício da Reitoria destaca-se dos anteriores, tanto em dimensão, devido às suas funções inerentes, bem como por ter duas entradas com pórticos, ambas decoradas com gravuras policromas incisas no ano em que foi inaugurado, 1961.

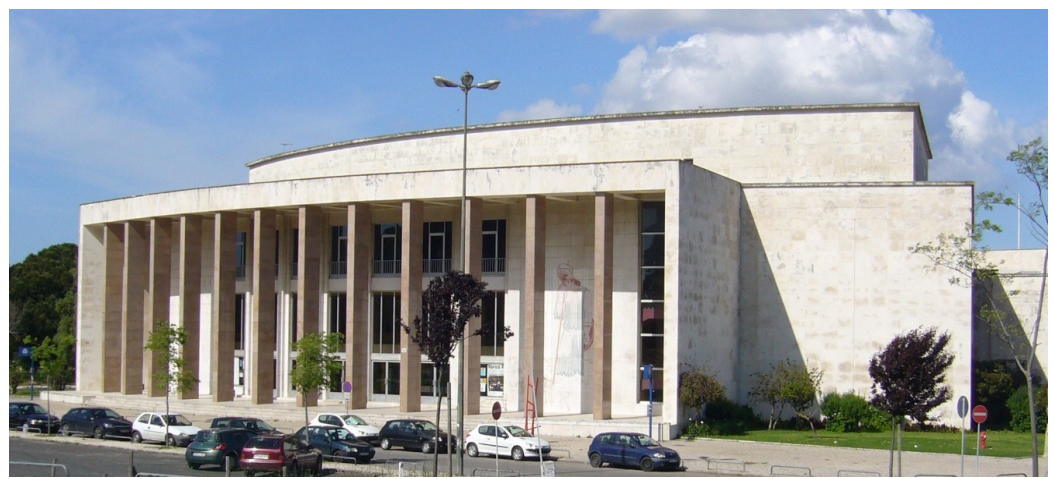

Fig, 24 - Pórtico de entrada poente da Reitoria (vestíbulo da Aula Magna). Fotografia: A. M. Pascoal, 2010.

O projecto decorativo foi aprovado pelo vogal da JNE Armando de Lucena $^{44}$; José-Augusto França, que não tece juízos de valor sobre as figuras greco-romanas colocadas na entrada que dá para o vestíbulo da Aula Magna, deprecia o conjunto do lado oposto, uma alegoria à cidade de Lisboa que encima uma profusa composição com referências ao zodíaco, que refere

43 Cf. J. de Almada Negreiros, «Prometeu. Ensaio espiritual da Europa», Obras Completas V, Lisboa, 1993, 87-114. Refira-se que em 15-IV-1944, Almada proferiu uma conferência na sede do Diário de Notícias, «Descobri a personalidade de Homero» ou «Quem era Homero?», não publicada; as ideias que então expôs foram também compiladas na colectânea póstuma Ver, que colige textos redigidos sobre esta temática em 1943.

44 ANTT, Junta Nacional da Educação, Actas das Sessões da $1^{\text {a }}$ Subsecção da $6^{\text {a }}$ Secção. Livro 103, Acta da 288ª sessão, 16 de Dezembro de 1960, f. 57. 
como animação das «paredes mortas duma arquitectura, (...) muito pobre de valores dinâmicos e modesta de concepção» 45 .

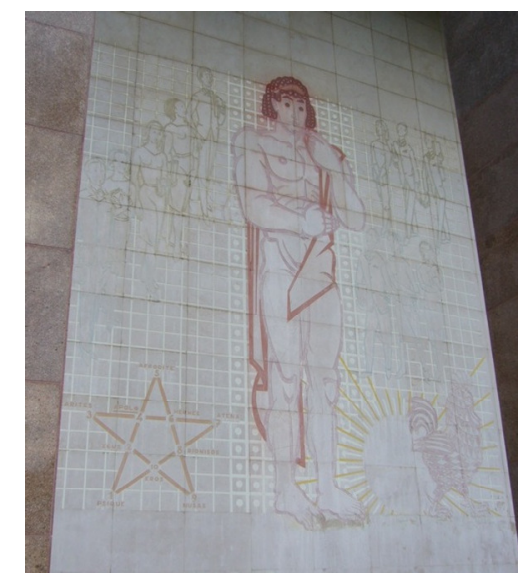

Fig. 25 - Apolo, gravura incisa, 1961.

Fotografia: A. M. Pascoal, 2010.

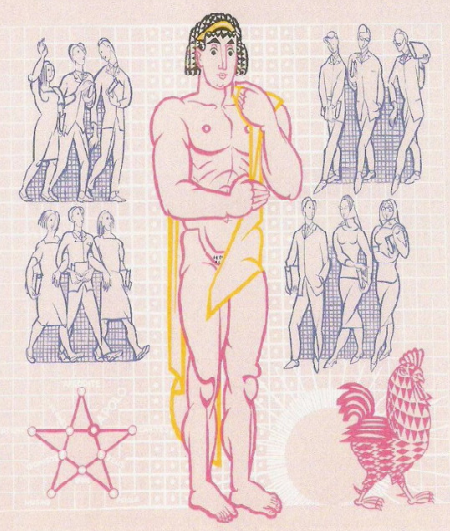

Fig. 26 - Apolo, estudo desenhado, sem data. Fonte: MOP/CANIU, O Novo Edifício da Reitoria da Universidade de Lisboa, Lisboa, s/n, 1961, sem paginação.

$\mathrm{Na}$ entrada poente, duas enormes figuras mitológicas, Apolo e Atena, orientam as composições definidas por uma malha ortogonal, estando ambos rodeados de mestres e estudantes. À esquerda da porta encontra-se Apolo, com musculatura acentuada, cabelo encaracolado adornado com uma fita e somente coberto por um longo pano posicionado sobre o ombro esquerdo, acompanhado pelo galo solar, frente ao astro, preconizador da iluminação intelectual que anuncia a luz nascente ${ }^{46}$. O deus do Sol, patrono das Belas Artes e símbolo da beleza e da clarividência, está rodeado por grupos de estudantes com livros nas mãos, em traje civil, desenhados num estilo algo caricatural, que o observam, posicionados de forma algo distinta do desenho prévio. Do lado direito, a majestosa e lúcida Atena guerreira encontra-se no centro da composição, com lança, égide e capacete, junto à coruja, que observa, ave nocturna figurada perante a lua e estrelas, simbolizando a

45 J.-A. França, op. cit, 170.

46 Cf. J. Chevalier, A. Gheerbrant, «Galo», Dicionário dos Símbolos. Mitos, sonhos, costumes, gestos, formas, figuras, cores, números, Lisboa, 1994, 344. 
sabedoria e o conhecimento racional ${ }^{47}$. Em seu redor, estudantes masculinos e femininas em pequenos grupos ouvem atentamente um mestre.

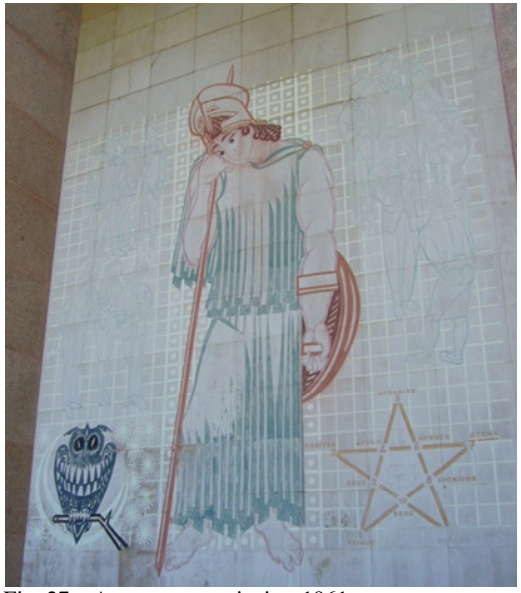

Fig. 27 - Atena, gravura incisa, 1961.

Fotografia: A. M. Pascoal, 2010.

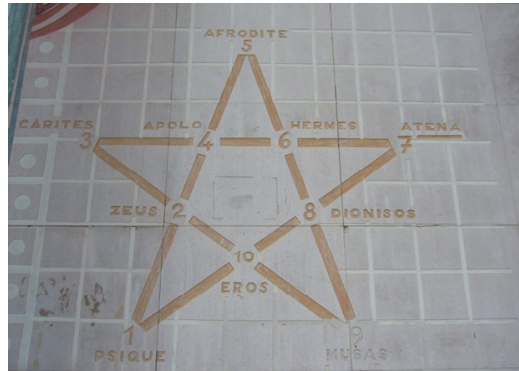

Fig. 28 - Pormenor do pentagrama representando as relações do «antropomorfismo-número», gravura incisa, 1961.

Fotografia: A. M. Pascoal, 2010

Em ambas as composições, o artista teve finalmente a possibilidade de materializar um assunto que muito lhe interessava e acerca do qual deixou alguns escritos: as relações do «antropomorfismo-número», nas quais faz correspondência entre as gerações de números e as divindades. Junto a cada uma das colossais figuras, foi colocado um pentagrama que marca nas intersecções das linhas «os dez lugares da colecção do número» ${ }^{48}$; cada ponto representa um número de 1 a 10 que corresponde, neste caso, a uma figura da mitologia greco-romana. Assim, a partir da ponta inferior esquerda, inscreveu «1-Psique, 2-Zeus, 3-Cárites, 4-Apolo, 5-Afrodite, 6-Hermes, 7-Atena, 8Dionisos, 9-Musas», sendo que em cada um dos pentagramas está sublinhado o nome do deus representado - Apolo e Atena, respectivamente.

$\mathrm{Na}$ Reitoria, as divindades representadas dignificam o edifício e constituem como que uma dedicação deste autêntico «templo do Saber»,

47 Idem, «Coruja», ibidem, 234.

48 J. de Almada Negreiros, Mito-Alegoria-Símbolo. Monólogo autodidacta na oficina de pintura, Lisboa, 1948, 21. 
sublinhando a mensagem de constante demanda pelo conhecimento que a Universidade desejava transmitir.

\section{Considerações Finais}

A Cidade Universitária foi uma das últimas obras pautadas pela colaboração entre Almada Negreiros e Porfírio Pardal Monteiro, que não chegou a ver o conjunto terminado. Nestes edifícios, onde a inspiração em elementos arquitectónicos classicistas é evidente, também a decoração aplicada comprova uma reminiscência de temas greco-romanos, presentes no imaginário colectivo e, especificamente, nos estudos desenvolvidos nas respectivas Faculdades. No entanto, em oposição a outros artistas que laboraram neste empreendimento e fixaram temáticas do foro mitológico, Almada Negreiros retratou as figuras de um modo sui generis - ao contrário de Leopoldo de Almeida, por exemplo, que para a Faculdade de Letras criou um harmónico baixo-relevo intitulado «Apolo cavalgando Pégaso preside ao Conselho das Musas», Almada não se limitou a representá-las conforme a tradição e os cânones academicamente instituídos. Criou figuras bidimensionais altamente expressivas, de volumetria praticamente ausente e apenas indicadas através dos contornos, numa paleta de cores focada no negro e no branco e nas cores primárias. É certo que as personagens, algo estilizadas, são facilmente identificáveis, concretamente através do vestuário, mas no que toca à fisionomia atestam o génio criativo de Almada e a sua destreza enquanto desenhador - mesmo que, nem sempre, tenha sido passada de igual forma do papel para a superfície de pedra. A retoma de uma técnica pouco frequente ${ }^{49}$, que o artista apenas veio a repetir no painel do átrio da sede da Fundação Gulbenkian e na decoração do Hotel Ritz, é igualmente ilustrativa da capacidade expressiva e inventiva, conferindo um carácter único à Universidade de Lisboa.

As figuras greco-romanas, bebidas em fontes literárias muito diversas, comprovam a complexidade e erudição da obra, cuja realização terá exigido uma investigação cuidada e um profundo conhecimento prévio por parte de

49 Sobre esta técnica do desenho inciso, Maria Augusta Maia registou que «para além de lhe oferecer a possibilidade de um desenvolvimento compositivo, (...) o reconduzia à mais recuada forma civilizacional e artística: às incisões ou relevos em pedra de povos como os Sumérios ou os Egípcios». Cf. Almada Negreiros. Um percurso possível, Lisboa, 1993, 69. 
Almada Negreiros. Há uma natural concentração na Faculdade de Direito, ilustrando as origens e os pilares que regem a disciplina - mesmo que se assista à inserção de figuras nitidamente preferidas pelo artista, que se sobrepuseram à figuração de personagens marcantes do Direito. Não obstante, no edifício dedicado a Letras incluíram-se obras basilares da cultura ocidental, diferenciadas por não estarem acompanhadas de legendas, transmitindo uma noção de ilustração directa e plena do texto escrito. Completadas pelas duas divindades mitológicas na Reitoria, no conjunto dos edifícios estão representadas, de forma relativamente exaustiva, as raízes greco-romanas da civilização europeia, numa espécie de concisa viagem histórica com exemplos de áreas como a Filosofia, a Literatura, o Direito, a Matemática e a Mitologia.

Composições diferenciadas das restantes que integram o programa artístico dos edifícios, estão imbuídas de um espírito próprio, embora sem perder o vínculo da imposição oficial de veicular uma mensagem concreta e importante para a Universidade. Porém, adequando-se às funções de cada edifício, mais do que propagar um discurso encomiástico de glorificação da instituição universitária de Lisboa, as gravuras incisas de Almada realçam o valor intrínseco das Faculdades e as especificidades de cada disciplina. Atestam a importância universal do conhecimento, bem como a importância das civilizações grega e romana para o progresso futuro da humanidade - e, por consequência, da própria Universidade e do ensino e da investigação nela desenvolvidos ${ }^{50}$.

\section{FONTES MANUSCRITAS}

\section{ARQUIVO NACIONAL DA TORRE DO TOMBO (ANTT)}

Junta Nacional da Educação, Actas das Sessões da $1^{\text {a }}$ Subsecção da $6^{\text {a }}$ Secção:

Livro 101, Acta da 242 a sessão, 11 de Janeiro de 1957, ff. 3 (verso) e 4. Livro 103, Acta da $288^{\text {a }}$ sessão, 16 de Dezembro de 1960, f. 57.

50 Agradecemos ao Prof. Doutor Nuno Simões Rodrigues a oportunidade de reflectir novamente sobre estas questões, através da redacção do presente texto, e por todo o apoio dado durante a nossa dissertação de Mestrado. Agradecemos também à Biblioteca de Arte da Fundação Gulbenkian e à Secretaria Geral do Ministério da Educação a autorização para reprodução de imagens. 


\section{FONTES PUBLICADAS}

\section{FONTES GREGAS E ROMANAS}

ÉSQUILO, Prometeu Agrilhoado (introdução, tradução e notas de Ana Paula Quintela Sottomayor), Lisboa, Edições 70, 2008.

HERACLITO, Fragmentos contextualizados (prefácio, apresentação, tradução e comentários de Alexandre Costa), edição bilingue, Lisboa, IN-CM, 2005.

HOMERO, Odisseia (tradução e introdução de Frederico Lourenço), $6^{\mathrm{a}}$ ed., Lisboa, Livros Cotovia, 2005.

PLATÃO, Êutifron, Apologia de Sócrates, Críton (tradução, introdução e notas de José Trindade dos Santos), $3^{\text {a }}$ ed., Lisboa, IN-CM, 1992.

ROCHA PEREIRA, Maria Helena da, Romana. Antologia da Cultura Latina, Porto, Edições Asa, 2005.

SÓFOCLES, Antígona (introdução, versão do grego e notas de Maria Helena da Rocha Pereira), 6 a ed., Lisboa, FCG/FCT, 1992.

TITO LÍVIO, The Early History of Rome (tradução e introdução de Aubrey de Sélincourt), Baltimore, Penguin Books, 1960.

\section{OUTRAS FONTES}

«Almada - do Genesis a Fernando Pessoa», Suplemento Vida Literária 157, Diário de Lisboa, $\mathrm{n}^{\circ} 13872$, ano 41ㅇ, 27 de Julho de 1961, pp. 13 e 15. MOP/CANIU, O Novo Edifício da Faculdade de Direito, Lisboa, s/n, 1957. , O Novo Edifício da Reitoria da Universidade de Lisboa, Lisboa, s/n, 1961.

NEGREIROS, José de Almada, Mito-Alegoria-Símbolo. Monólogo autodidacta na oficina de pintura, Lisboa, Livraria Sá da Costa, 1948. , Ver, Lisboa, Arcádia, 1982. , Obras Completas, vols. V e VI, Lisboa, IN-CM, 1992-1993.

\section{BIBLIOGRAFIA}

AAVV, Almada Negreiros. Um percurso possível, Lisboa, IPPAR/IN-CM, 1993.

CASTRO, Luís F. N. A., Almada Negreiros: Herança Grega e Teoria das Proporções Harmónicas, 2 vols., Tese de Mestrado em Teorias da Arte, Faculdade de Belas Artes da Universidade de Lisboa, 2003.

FRANÇA, José-Augusto, Almada. O Português sem Mestre, Lisboa, Estúdios Cor, 1974. 
KIRK, G. et al., Os Filósofos Pré-Socráticos. História crítica com selecção de textos, $4^{\mathrm{a}}$ edição, Lisboa, FCG, 1994.

MARTINO, Francesco de, Storia della Constituzione Romana, vol. I, $2^{\mathrm{a}}$ ed., Nápoles, Eugenio Jovene, 1972.

PASCOAL, Ana Mehnert, A Cidade do Saber. Estudo do Património Artístico Integrado nos edifícios projectados pelo arquitecto Porfírio Pardal Monteiro para a Cidade Universitária de Lisboa (1934-1961), Dissertação de Mestrado em Arte, Património e Teoria do Restauro, Faculdade de Letras da Universidade de Lisboa, 2010.

PEDROSA, Patrícia Santos, Cidade Universitária de Lisboa (1911-1950): génese de uma difícil territorialização, Lisboa, Edições Colibri, 2008.

ROSMANINHO, Nuno, O Poder da Arte. O Estado Novo e a Cidade Universitária de Coimbra, Coimbra, Imprensa da Universidade, 2006.

TEIXEIRA, José de Monterroso (coord. cient.), Almada. A cena do corpo: catálogo de exposição, Lisboa, Fundação das Descobertas/Centro Cultural de Belém, 1993.

VIEIRA, Joaquim, Almada Negreiros, colecção «Fotobiografias Século XX», Lisboa, Círculo de Leitores, 2001. 